\title{
LOW-COST FLEET MANAGEMENT SOLUTIONS IN THE FRAMEWORK OF EMERGING MARKETS
}

\author{
Dimitra Chondrogianni ${ }^{1}$, Christos Gioldasis ${ }^{2}$, and Yorgos J. Stephanedes, P.E. ${ }^{3}$
}

\begin{abstract}
Implementation of ITS solutions in the emerging market of Egypt is at an early stage, yet has made significant progress. In the framework of PHAROS project, low-cost smart solutions have been developed for fleet managers to facilitate efficient route choices and eco-driving that minimize fuel consumption and carbon emissions. These solutions were integrated in an existing fleet management system. This paper presents the theoretical and practical formulation of the rescheduling component added to the already existing fleet management system. The rescheduling component is based on the development of an eco-path that considers the "cost" between two consecutive nodes. By the term "cost", more parameters such as path length, travel time, operating costs, energy consumption required for each route, are taken into account. Based on the above decision-routing parameters, through the use of a routing algorithm, the optimal path between the origin and the destination node is proposed.
\end{abstract}

Keywords: ITS, fleet management, rescheduling, emerging markets.

\section{INTRODUCTION}

PHAROS is an EU-Egypt funded project which developed low-cost smart solutions for fleet managers to facilitate efficient route choices and eco-driving that minimize fuel consumption and carbon emissions. Algorithms for travel time estimation and fuel consumption estimation (Stephanedes et al. 2016) have been developed and integrated into the existing fleet management system "Altair" developed by Softec International Company and used by various customer-companies in Egypt.

In addition to the above models, various traffic management techniques have been developed in order to check the limitations set by the infrastructure and environment of a developing country. In this paper the scheduling/rescheduling component that has been added to the original system is presented, with focus on the background of the scheduling/rescheduling component and its formulation. A case study is also included.

1 PhD candidate, Department of Civil Engineering, University of Patras, Patras, Greece, dimitradani90@gmail.com

2 PhD candidate, Department of Civil Engineering, University of Patras, Patras, Greece chgioldasis@upatras.gr

3 Professor, Department of Civil Engineering, Director of ITS Program, University of Patras, Patras, Greece, yjste@upatras.gr 


\section{SCHEDULING / RESCHEDULING}

\subsection{Introduction}

Optimizing a route helps drivers navigate the roadway, avoid traffic challenges, reduce idling and other delays, saving precious fuel. Keeping drivers well informed helps them make the best route revisions. Moving from a traditional dispatcher process to an automated GPS-driven fleet tracking and management solution can increase productivity by $25 \%$ or more as the application can track and contact multiple drivers simultaneously as opposed to phone or radio contact to multiple drivers in an effort to find vehicles close to a specific location.

When a vehicle on a scheduled trip breaks down, one or more vehicles need to be rescheduled to serve the customers on that trip with minimum additional operating and delay costs. The main objective of the vehicle rescheduling problem (VRSP) is to minimize operation and delay costs, while serving the passengers/cargo on the disrupted trip and completing all remaining trips that include the disrupted one.

It is generally believed that adaptive routing will save travel time and enhance travel time reliability. For example, in a network with random incidents, if one does not adapt to an incident scenario, one could be stuck in the incident link for a very long time. In particular, the vehicle rescheduling problem (VRSP) arises when a previously assigned trip is disrupted. A traffic accident, a medical emergency and a breakdown of a vehicle are examples of possible disruptions that demand the rescheduling of vehicle trips. However, if adequate online information is available about the incident, and the traveller adapts to it by taking an alternative route, he/she can save travel time compared to the non-adaptive case. The adaptive solution also ensures that the travel time is not prohibitively high in incident scenarios, and is more reliable.

The vehicle rescheduling problem (VRSP) could be investigated in order to quantify and assess the changes in operating costs, schedule disruption costs, and trip cancellation costs. In these cases, different models for addressing the problem could be formulated, and several fast algorithms could be developed for arriving at a feasible solution, including parallel synchronous auction algorithms or Dijkstra's algorithm.

The problem of optimal adaptive routing decision making for individual travellers has been studied (Gao and Chabini 2006). Especially for the vehicle rescheduling problem, several survey articles summarise approaches and provide useful references to the large number of journal articles that have been written on this topic; for example Golden and Assad (1988), Toth and Vigo (2001), Laporte and Nobert (1987), Agarwal et al., (1989) have proposed optimal approaches to solve the VRSP.

\subsection{Parameters}

The parameters on which the rescheduling is based are presented below: fuel consumption for trucks (lt), number of lanes per direction, distance from the node to the final destination, and travel time (min). Each criterion was evaluated in a different way according to whether it was considered as a positive parameter that facilitates the travel or had a negative impact on the result.

\subsubsection{Fuel consumption}

In implementing on-trip scheduling/re-scheduling, the fuel consumption parameter is of high importance in order to recommend the most ecological routes. The eco paths are evaluated based on the fuel consumption that each route requests. 
During the PHAROS project, a model that evaluates different factors affecting fuel consumption was proposed. Based on this model, the fuel consumption should be estimated as the component of the fuel consumption in motion and for reporting purposes motion on idle. (National Research Council,2010 \& Argonne National Laboratory, accessed 2014).

The fuel consumption from one node $\mathrm{i}$ to any other $\mathrm{j}$ is symbolized as FCij. For a network of $\mathrm{k}$ nodes, the fuel consumption values are presented in Table 1.

Table 1: Fuel consumption for each path

\begin{tabular}{cccccc}
\hline Path $\mathrm{ij}$ & $\begin{array}{c}\text { Fuel } \\
\text { Consumption }\end{array}$ & Path $\mathrm{ij}$ & $\begin{array}{c}\text { Fuel } \\
\text { Consumption }\end{array}$ & Path $\mathrm{ij}$ & $\begin{array}{c}\text { Fuel } \\
\text { Consumption }\end{array}$ \\
\hline $1--2$ & $F C_{12}$ & $3--1$ & $F C_{31}$ & $5--1$ & $F C_{51}$ \\
$1--3$ & $F C_{13}$ & $3--2$ & $F C_{32}$ & $5--2$ & $F C_{52}$ \\
$\ldots$ & $\ldots$ & $\ldots$ & $\ldots$ & $\ldots$ & $\ldots$ \\
$1--\mathrm{k}$ & $F C_{1 \mathrm{k}}$ & $3--\mathrm{k}$ & $F C_{3 \mathrm{k}}$ & $5--\mathrm{k}$ & $F C_{5 \mathrm{k}}$ \\
\hline $2--1$ & $F C_{21}$ & $4--1$ & $F C_{41}$ & $\mathrm{k}-1$ & $F C_{\mathrm{k} 1}$ \\
$2--3$ & $F C_{23}$ & $4--2$ & $F C_{42}$ & $\mathrm{k}--2$ & $F C_{\mathrm{k} 2}$ \\
$\ldots$ & $\ldots$ & $\ldots$ & $\ldots$ & $\ldots$ & $\ldots$ \\
$2--\mathrm{k}$ & $F C_{2 \mathrm{k}}$ & $4--\mathrm{k}$ & $F C_{4 \mathrm{k}}$ & $\mathrm{k}--(\mathrm{k}-1)$ & $F C_{\mathrm{k}(\mathrm{k}-1)}$ \\
\hline
\end{tabular}

\subsubsection{Number of lanes per direction}

The criterion regarding the number of lanes in each direction is considered to be of high importance in the decision making process. Taking into consideration the Cairo road infrastructure, more than two road lanes per direction assures more road capacity and a safer and more comfortable trip. In the proposed routing process, there are two options for rating each road connection: A) each road with two or fewer lanes gets 0 points B) 0.5 points are given for each road with more than two lanes. The following table (Table 2) shows the rating based on the second criterion:

Table 1: Number of lanes per direction

\begin{tabular}{cllll}
\hline Path $(\mathrm{i} \rightarrow \mathrm{j})$ & \multicolumn{2}{c}{ Number of lanes } & \multicolumn{2}{c}{ Rating } \\
\hline $\mathrm{i}-\mathrm{j}$ & $>2$ & $\leq 2$ & 0,5 & 0 \\
\hline
\end{tabular}

\subsubsection{Distance from final destination}

During the re-scheduling process, the system must select the path with the lowest cost. The distance of each of the nodes that belong to the possible paths, from the final destination node is critical. The selection of the optimal path is influenced by determining the node that is closer to the final goal.

For the reasons mentioned above, the distance of each node from the final destination node $\left(D_{\mathrm{jk}}\right)$ is multiplied by a weight of -0.1 . 
Table 3: Distance from final destination $(\mathrm{km})$

\begin{tabular}{ccc}
\hline Path $(\mathrm{i} \rightarrow \mathrm{j})$ & Distance & Rating \\
\hline $\mathrm{i}-\mathrm{j}$ & $D_{\mathrm{jk}}$ & $-0.1^{*} D_{\mathrm{jk}}$ \\
\hline
\end{tabular}

\subsubsection{Travel time}

The last parameter is the travel time between the nodes. Travel time greatly affects the final selection of the optimal path in an inverse way. Considering that the shortest travel time should be chosen to avoid delays, the travel time regarding each path is multiplied by a weight of -0.1 .

Table 4: Travel time (min)

\begin{tabular}{ccc}
\hline Path $(\mathrm{i} \rightarrow \mathrm{j})$ & Distance & Rating \\
\hline $\mathrm{i}-\mathrm{j}$ & $T_{\mathrm{ij}}$ & $-0.1^{*} T_{\mathrm{ij}}$ \\
\hline
\end{tabular}

\subsection{Decision making process}

At first, when a scheduling/rescheduling process is requested all possible routes between an origin node $\mathrm{i}$ and a destination node $\mathrm{k}$ must be determined.

As a second step, the different parameters (FCij, Lij, Djk, Tij), mentioned above, for the paths that form the different routes are calculated and the rating for each path is given by the equation (1)

$$
R i j=F C i j+L i j+(-0.1 * D j k)+(-0.1 * T i \mathrm{ij})
$$

In particular, in a track of $k$ nodes that could be described as sequence $123 \ldots$ (k-1) $k$, the total rating is given in Table 5 .

Table 5: Calculation of total rating

\begin{tabular}{cccccc}
\hline Sequence & \multicolumn{5}{c}{ Paths } \\
\hline & $1--2$ & $2--3$ & $\ldots$ & $(\mathrm{k}-2)-(\mathrm{k}-1)$ & $(\mathrm{k}-1)--\mathrm{k}$ \\
$123 \ldots(\mathrm{k}-1) \mathrm{k}$ & & & & & $R_{12}+R_{23}+\ldots+R_{(\mathrm{k}-2)(\mathrm{k}-1)}+$ \\
& $R_{12}$ & $R_{12}+R_{23}$ & $\ldots$ & $R_{12}+R_{23}+\ldots+R_{(\mathrm{k}-2)(\mathrm{k}-1)}$ & $R_{\mathrm{k}(\mathrm{k}-1)}$ \\
\hline
\end{tabular}

The total rating for each possible route is given by equation (2).

$$
R=R 12+R 23+R 34+\cdots+R(k-2)(k-1)+R(k-1) k
$$

By comparing the evaluation of each possible path, the routing engine selects the one with the minimum value, as described in Figure 1. Finally, the optimal route with the least cost is presented to the user as the recommended solution to his request. 


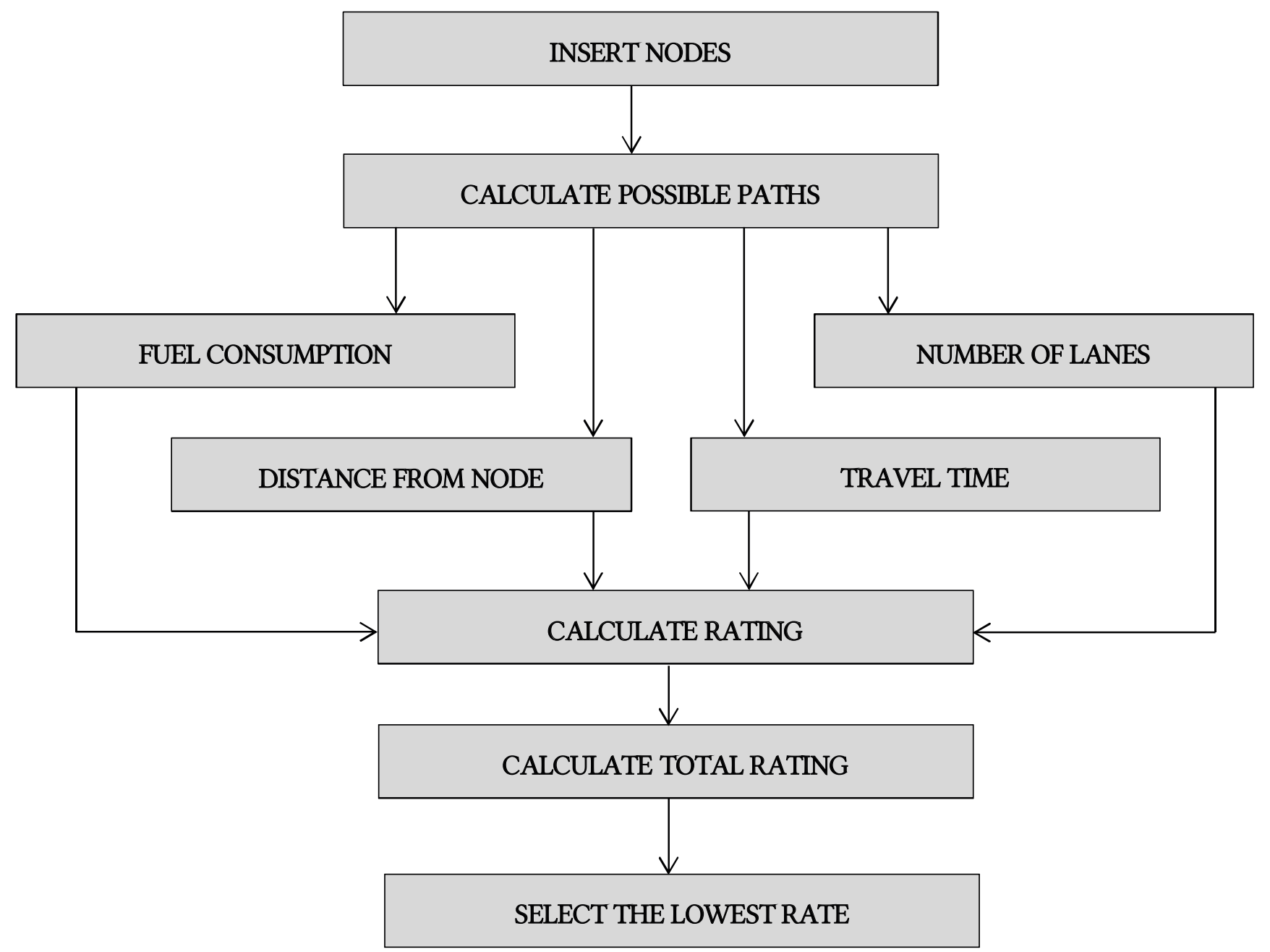

Figure 1: Flow chart of algorithm logical sequence

\section{CASE STUDY}

A case study of schedule update is presented below, showing how the final route is selected when scheduling/re-scheduling is required.

\subsection{Path: Ring Rd - Suez Rd}

At first, Ring Rd is set as origin, and Suez Rd is the destination. The length of path between the two nodes is given in Table 6 .

Table 6: Origin and destination of trip

\begin{tabular}{ccc}
\hline Origin & Destination & Path $(\mathbf{k m})$ \\
\hline Ring Rd, Cairo & Suez Rd & 21,6 \\
\hline
\end{tabular}

The shortest path that connects origin to destination is presented in Figure 2. 


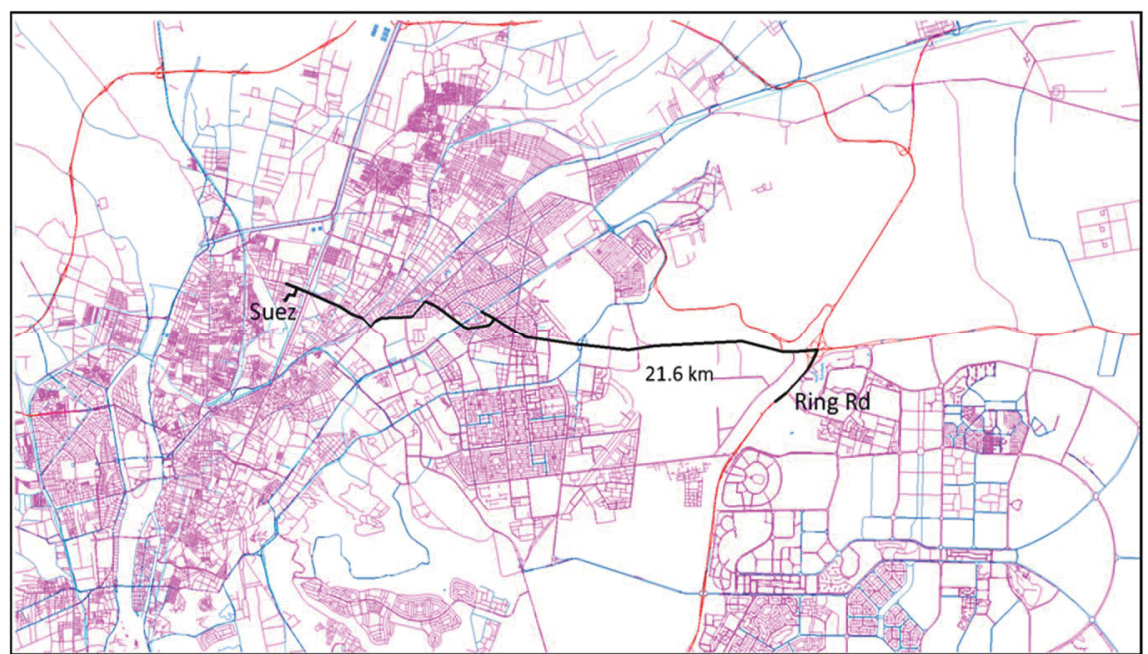

Figure 2: Shortest path connecting the nodes displayed on the Greater Cairo map

Owing to new data on changes to the truck schedule, a request for re-scheduling accommodates a user that has to visit two more nodes, El-Nasr Rd and El Orouba.

The name and coordinates of the four nodes used in rescheduling are presented in Table 7 and Figure 3.

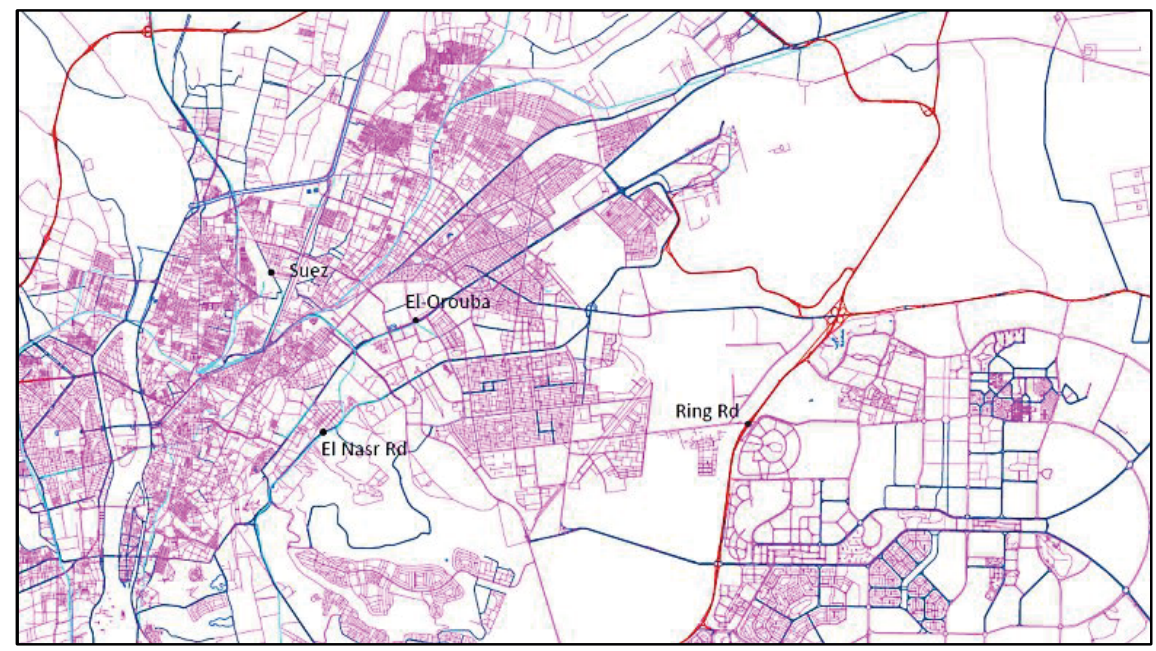

Figure 3: The 4 nodes displayed on the Greater Cairo map

Table 7: Name and coordinates of four nodes

\begin{tabular}{cccc}
\hline Nodes & Name & Origin X (Longitude) & Origin Y (Latitude) \\
\hline 1 & Ring Rd & 30.0477367 & 31.4064844 \\
2 & El Nasr & 30.058445 & 31.30243 \\
3 & El Orouba & 30.088885 & 31.330483 \\
4 & Suez Rd & 30.0895354 & 31.2681058 \\
\hline
\end{tabular}

For the above 4 nodes 6 different paths are calculated. The distance along each path, and the fuel consumption for each distance, as well as the number of lanes in each path 
and the distance from final path node $\mathrm{j}$ to destination node $\mathrm{k}$ are shown on the following Tables 8 and 9 .

Table 10 shows the travel time for each path and the calculated rating based on equation (1) for each path among the 4 nodes.

Table 8: Distance and fuel consumption for each path

\begin{tabular}{ccc}
\hline Path $\mathbf{i j}$ & Distance $(\mathrm{km})$ & Fuel Consumption $(\mathrm{lt})$ \\
\hline 12 & 19 & 7.523 \\
13 & 16 & 6.336 \\
14 & 21 & 8.315 \\
21 & 17 & 6.732 \\
23 & 7 & 2.772 \\
24 & 8 & 3.168 \\
31 & 23 & 9.107 \\
32 & 5 & 1.980 \\
34 & 9 & 3.564 \\
41 & 23 & 9.107 \\
42 & 7 & 2.772 \\
43 & 9 & 3.564 \\
\hline
\end{tabular}

Table 9: Number of lanes and distance from destination node for each path

\begin{tabular}{ccc}
\hline Path ij & Lij & Djk (km) \\
\hline 12 & 0.5 & 17 \\
13 & 0.5 & 23 \\
14 & 0 & 23 \\
21 & 0.5 & 0 \\
23 & 0.5 & 23 \\
24 & 0 & 23 \\
31 & 0.5 & 0 \\
32 & 0.5 & 17 \\
34 & 0.5 & 23 \\
41 & 0 & 0 \\
42 & 0 & 17 \\
43 & 0 & 23 \\
\hline
\end{tabular}


Table 10: Travel time and rating for each path

\begin{tabular}{ccc}
\hline Path ij & Tij(min) & Rij \\
\hline 12 & 30 & 3.323 \\
13 & 28 & 1.736 \\
14 & 50 & 1.015 \\
21 & 19 & 5.332 \\
23 & 25 & -1.528 \\
24 & 32 & -2.332 \\
31 & 32 & 6.407 \\
32 & 13 & -0.520 \\
34 & 28 & -1.036 \\
41 & 43 & 4.807 \\
42 & 25 & -1.428 \\
43 & 35 & -2.236 \\
\hline
\end{tabular}

Taking into consideration the above table with the results of Rij, and based on equation (2), the total rating for each possible path sequence is calculated in Table 11.

Table 11: Total rating for each path sequence

\begin{tabular}{cc}
\hline Possible Routes & $\mathrm{R}$ \\
\hline 12341 & 5.566 \\
12431 & 5.162 \\
13241 & 3.691 \\
13421 & 4.604 \\
\hline 14231 & 3.391 \\
\hline 14321 & 3.591 \\
\hline
\end{tabular}

Route 14231 is recommended as the optimal solution for the scheduling/rescheduling problem of the case study, based on fuel consumption, travel time, distance from the destination, and road capacity. 


\section{CONCLUSIONS}

The scheduling/rescheduling component development is part of a wider project to promote eco-friendly and low-cost ITS solutions in Egypt. This component has been fully implemented and successfully tested. However, further ITS-related work, such as a dynamic traffic assignment, has not been implemented owing to the limitations set by the lack of infrastructure that would be used to provide adequate data. It has been concluded that Egypt needs to further invest in ITS development by approaching an ITS roadmap along the following steps in Figure 4.

ITS Vision

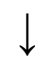

ITS Mission

$\downarrow$

ITS National Strategy

$\downarrow$

ITS Architecture

Figure 4: Suggested steps of ITS development in Egypt

Moreover, based on international common practice, it was suggested that two processes must run in tandem, the establishment of a national ITS society and the development of a government-led national strategy, with a clear owner within the government.

\section{ACKNOWLEDGMENTS}

This research was co-funded by the Research, Development and Innovation Programme (RDI), A Programme of the Ministry of Higher Education and Scientific Research of Egypt, funded by the EU-Egypt Innovation Fund (EIFF) of the European Union. The research is an activity of project PHAROS Eco-routing and Fleet Management Systems. The project is implemented by the consortium led by the Center for Environment and Development in the Arab Region and Europe (CEDARE) and the partners; University of Patras, SOFTEC International, Eindhoven University of Technology (TU/e), University of Utrecht, and associate partner, Ministry of Communication and Information Technology of Egypt. The authors acknowledge SOFTEC International for the provision of data. We acknowledge support by European Territorial Cooperation Programme (ETCP) project, "GUIDEPORT: Integrated accessibility and routing guidance platform for safe multimodal transport in sustainable smart ports and regions", Managing Authority of European Territorial Cooperation Programmes, Joint Technical Secretariat of ETCP "Greece-Italy 2007-2013", 3512/25.06.2012/902069 that has been co-funded by EU. 


\section{REFERENCES}

Agarwal, Y., Mathur, K. and Salkin, H.M. (1989). A Set-Partitioning-Based Exact Algorithm for the Vehicle Routing Problem, Networks, 19(7),731-749.

Gao, S., and Chabini, I. (2006). Optimal routing policy problems in stochastic timedependent networks. Transportation Research Part B: Methodological, 40(2), 93-122.

Golden, B. I. and Assad A. (1988.): Vehicle Routing with Time-Window Constraints: Algorithmic Solutions. Vol. 15 of American Series in Mathematical and Management Sciences. American Sciences Press, Inc., Columbus, Ohio, pp. 251-428.

Laporte, G. N. (1987). The Vehicle Routing Problem: An overview of exact and approximate algorithms. European Journal of Operational Research 59, NorthHolland

Stephanedes Y., Sipetas C., Gioldasis C., El-Dorghamy A. (2016). Estimation of fuel consumption in urban networks from GPS data in fleet monitoring, 11th ITS European Congress, Glasgow, Scotland.

Toth, P., Vigo, D. (2001). The Vehicle Routing Problem. Monographs on Discrete Mathematics and Applications. S.I.A.M., Philadelphia. 